Nuestra época de caos está diciendo que es nuestra época de formación. Nos conmovemos porque buscamos nuestro equilibrio. Esta desorientación es sólo el fracaso rotundo de las aplicaciones disímiles, el rechazo de lo que no se adapta a la idiosincrasia americana. Y es saludable por todo lo que significa en esfuerzo esta perenne agitación de pueblos, porque ello demuestra que no ha cuajado un espíritu de conformismoimposible en razas jóvenes-sino que el hombre va hacia su liberación y superación por medio de su propio conocimiento.

Uno de los pueblos más constantemente convulsionados es Méjico. Rojas leyendas se ciernen sobre su historia. Pero no hay que olvidar que es Méjico el pueblo de mayor perfil americano, el de más homogeneidad racial y el que mayores luchas ha tenido que sostener-y sostiene-con sus expoliadores, los españoles de la conquista y de la independencia, los frailes y los imperialistas del norte.

Sin embargo, nada de ésto ha destruído la raíz mejicanista. $\mathrm{Y}$ hay una conciencia mejicana, como hay un arte mejicano, expresión la más alta de un pueblo. La pintura popular de Méjico, reconocida por la crítica europea como una asombrosa demostración de sentido estético-prueba de dotes superiores-, la música mejicana, la escultura mejicana desde su prehistoria, la enorme capacidad popular para todas las artes domésticas, dicen con el tono más preciso que ese conglomerado de "salvajes», de "bandoleros» y de «matones»-según las informaciones de las agencias cablegráficas-es un gallardo trozo de la América nuestra, lo más representativo y lo que con mayor orgullo debiéramos exhibir como una definitiva muestra de americanidad.-M A G D A P O R T A L.

\title{
SOMERA REVISTA MILITAR A ALGUNAS NOVELAS DE LA GUERRA
}

\section{I.-INTRODUCCIón}

舅

ENGO alineadas en mi mesa, frente a mí, las siguientes novelas de la guerra, a las cuales pretendo revisar con mirada de soldado: La Llamada del Suelo y La Tormenta sobre el jardín de Cándido por Adrián Bertrand; Mi Pieza por Pablo I intier; Al servicio de Alemania y Colette Baudoche por Mauricio Barrès; El Emboscado por Pablo Margueritte; El fuego por 
Henry Barbusse; Sin novedad en el frente por E. M. Remarque; El Sargento Grischa por Arnold Zweig; Los que teníamos 12 años por Ernesto Glaeser; Guerra por Luwigd Renn, y algunos capítulos de En la boca de la muerte por Franz Schanwecher.

No se me oculta que es ardua y difícil mi tarea, pero la emprendo con" verdadero regocijo. Es posible que el ojo militar, educado en la crítica del detalle material inadvertido, sorprenda más fácilmente la falta de un botón en el uniforme que el exceso de talento de un novelista; pero no obstante el tema tienta a un soldado porque lo sabe suyo, desde el punto de vista militar, y más aun si se considera explicable y hasta perdonable que ese soldado tenga afición literaria.

\section{II.-Algunas nOvelas escritas EN El Frente Francés}

Con este título me refiero a las novelas escritas por los franceses, que fueron los primeros en abordar el tema y icon qué abundancia! Hace pocos años se hizo una encuesta en París para establecer quién era el mejor escritor vivo de Francia. Clemenceau respondió:

Es difícil, si no imposible, responder quien es el mejor escritor de Francia, sencillamente porque cada francés es un escritor.

Admirable respuesta que sintetiza la verdad y revela una gran comprensión del espíritu francés. Efectivamente, durante la guerra cada soldado francés escribía sobre las rodillas o en el reverso de su mochila, sus impresiones, bajo el fuego inclemente de la artillería alemana. Los hombres de ciencias o profesionales (profesores, sabios, ingenieros), transformados en soldados, suboficiales $\mathrm{u}$ oficiales, por el constante llamado de las reservas, y que contribuyeron no poco con sus luces a hacer la guerra más poderosa e inteligente, eran antes que nada escritores y artistas que necesitaban, en forma imperiosa, escribir sus frescas impresiones para enviarlas al hogar o a la amada. Por desgracia, todas estas páginas íntimas se han perdido en el secreto de los afectos. En general, las novelas de la guerra escritas por franceses se caracterizan por su buen gusto, por su mesura, por su equilibrio, por la belleza de su estilo y por la profundidad filosófica y humana con que los autores abordaron el tema.

No es posible, por ejemplo, leer las dos obras de Bertrand citadas al iniciar este trabajo, sin estremecerse de emoción. 
La Llamada del Suelo es acaso la obra más bella de este género de las que yo he leído. La obra de Pablo Lintier, Mi Pieza, es también un libro admirable. Su autor, que desempeñó en la guerra el obscuro y glorioso puesto de sargento comandante de pieza de artillería, escribió, hasta en la cuna de su propio cañón enrojecido por el fuego, sus impresiones personales. Obtuvo así una obra vívida y real, de un valor de sugestión inimitable.

Los franceses, ya sea explotando el problema sociológico nacionalista de Alsacia-Lorena, en la obra de Barrès, o el de los remisos y emboscados para eludir el llamado de las filas clareadas por la muerte, que pedían reemplazo, en la novela de Pablo Margueritte, o hablando de los animales en la guerra, en La Tormenta sobre el Jardín de Cándido, de Adrián Bertrand, muestran siempre la discreción y la gracia latinas, aunque no tengan molde clásico. Son patriotas sin ser patrioteros, son artistas antes que ser soldados, y son los mejores soldados, los más conscientes de la guerra y de la disciplina. Y es curioso advertir que, en el momento preciso de estallar el conflicto mundial, los franceses tenían fama de antimilitaristas, sobre todo la clase llamada «intelectual».

No obstante, es justo reconocer, y lo reconoce Blasco Ibáñez en uno de sus interesantes prólogos de la Novela Literaria, diciendo:

Los franceses rebeldes $\mathrm{y}$ anti-militaristas por naturaleza, miraban a su E,jército con infinito desprecio. Hay que haber presenciado la movilización francesa de 1914, en esta Francia donde abundaban semanas antes los mítines anti-militaristas. El porcentaje de los desertores resultó insignificante comparado con la enorme masa llamada a las armas. Y de esta insignificante cantidad de hombres que faltaron al llamamiento-residuo que existe en todo pueblo-muchos fueron gentes de posición social, que podían pagar los medios ocultos para transponer las fronteras.

\section{III.-OTRAS, ESCRITAS POR ALEMANES}

La mayor parte de las novelas escritas por alemanes, empezando por la discutida obra de Remarque Sin novedad en el frente, son deficientes desde el punto de vista artístico-literario. Su grandeza reside más en la desnudez y audacia de los conceptos, que parecen emitidos con cierta ingenuidad chocante a los ojos latinos. Los alemanes no entienden de medidas ni difusiones de colores. Son chillones y caen pronto, sin advertirlo acaso, en el mal gusto. Una escena cruda, realista, descrita por un francés, es grosera en manos de un alemán. 
Un rasgo tierno en el teatro francés resulta infantil en la escena alemana. No aciertan casi nunca en la nota justa. Hasta el cine alemán, tanto en su concepción como en la interpretación hecha por artistas alemanes, resulta distante de lo que se quiere obtener. $\mathrm{O}$ mucho o poco; pero raras veces la exacta medida, el equilibrio estable de la verdadera obra de arte.

S6́lo así se explica que no hallemos belleza en las novelas de la guerra escritas por alemanes. Y si buscamos la verdad en ellos, la encontramos a veces tan exagerada, que nos parece ficción. Así tenemos que el anti-militarismo de que tantagala parece hacer Remarque en su libro, parezca algo insólito expresado y sentido por un alemán. Barbusse, en su libro $\mathrm{Cla}$ ridad es más inteligente, más razonable acaso en sus argumentos contra el uniforme del soldado. Este último libro se lee con cierto deleite, aunque sustente ideas adversas, diametralmente opuestas a las nuestras.

IV.-Lo QUe Dicen LOS NOVELISTAS DE LA EVOLUCIÓN DE GUERRA Y DE SU ESCUELA

Los novelistas suelen emitir juicios un tanto aventurados de hechos que no conocen, ya sea por fal,ta de informaciones o por error de concepto; hecho por lo demás perfectamente explicable y perdonable hasta cierto punto. Así tenemos a Blasco Ibáñez hablando de cuestiones militares y poniendo en boca de un ilustre militar francés (que no cita) las siguientes palabras:

Hemos pasado-dice-todo un siglo estudiando y comentando las campañas de Napoleón, como si después de él no hubiese nada. ¡Ah Napoleón! Aun no hace un siglo que murió, pero en sus tiempos el fusil cargado lentatamente por la boca alcanzaba a trescientos metros. Si Bonaparte resucitase ahora se sentiría completamente desorientado, como si hubiese resurgido en otro planeta, y necesitaría escuchar con sumisión de discípulo las explicaciones de cualquier ingeniero industrial, convertido por la movilización en Capitán de Artillería.

Estas frases del ilustre novelista, puestas uno de sus pr6logos, constituyen un lamentable error. En efecto. como la admirable evolución de la guerra se refiere exclusivamente a un cambio en los medios materiales de combate y, por ende, de las formaciones, sin que los grandes principios tácticos hayan variado en lo más mínimo, se comprenderá que. en la simpática y curiosa resurrección de Napoleón sugerida por la fan- 
tasía de Blasco Ibáñez (o de su ilustre general) el genio de la guerra bien poco tendría que aprender y sí mucho que enseñar. No olvidemos que así como hay clásicos en la literatura, que aun no han sido superados, también hay un clásico en el arte de la guerra: Napoleón Bonaparte. Así como este ejemplo citado habría muchos otros, interesantes, que se refieren a crítica militar de parte de escritores, en quienes se advierte, a la legua, que nunca han sido militares profesionales.

La misma jerga soldadesca emplea denominaciones características, que, al ser suplidas o mal reemplazadas por otras, resultan forzadas y extrañas a los oídos de los que no son del "medio». Y por desgracia, los escritores de la guerra-por lo menos estos que yo he leído-caen en estos pequeños errores de forma o de concepto, que restan algo de valor al relato.

\section{V.-LA DISCIPLINA MILITAR EN AMBOS FRENTES}

Los oficiales alemanes, que habían ejercitado, durante la paz, una disciplina odiosa y poco humana, a base de intransigencias, recibieron durante la guerra muchas revelaciones insólitas, que más de algo les dieron que pensar a los que no las experimentaron en pellejo propio y salieron con vida.

No fué extraño el caso, entre los alemanes, de tropas abiertamente insubordinadas, que se negaban rotundamente a obedecer, no tanto por el pánico producido por los infernales nuevos medios de combate: bombas, lanza-minas, lanza-llamas, cañones de increíble potencia, tanques, etc., como por rebelarse contra la tiranía de comandantes subalternos inescrupulosos, que sólo concebían la disciplina del terror. Muchos de estos oficiales murieron, misteriosamente, por una bala salida de las mismas fracciones de tropas que comandaban.

Hay «barra»o no hay «barra», se preguntaban los soldados alemanes en su jerga militar, frecuentemente, cada vez que un oficial daba una voz de mando o impartía una orden. Si había "barra» (ambiente para el oficial, o el ámino y la voluntad de obedecerle) se respetaba el designio del oficial. Si no "había barra", ya podía enronquecer a gritos, que nadie había de cotizarle. Si el oficial había sido benévolo y se había hecho admirar y estimar por su preparación e inteligencia, su energía-indispensable en el que manda-salvaba la situación, y el jefe se imponía; pero si el oficial no era un adicto convencido de su tropa y si aquella no había visto en él afecto y verdadero espíritu de sacrificio ejemplarizador, el oficial 
pagaba con su vida su dureza y su frialdad o indolencia anteriores.

En cambio en el frente francés, en el cual la disciplina consciente había hecho escuela, se vió en la tropa una mayor abnegación y mayor comprensión de los deberes recíprocos de oficiales y soldados. Estaba ahí el hilo sutil, impalpable, que unía al jefe y al subordinado. En la calle un soldado francés pedía fuego para encender su cigarrillo a su teniente que pasaba, y esto no excluía el respeto ni las consideraciones debida al oficial sino al contrario, quizás si la cortesía las acrecentaba. Un soldado alemán no se hubiera atrevido a hablar al oficial; la rigidez de los principios disciplinarios impuestos a su cerebro, no habría permitido esta familiaridad.

Antes de la batalla del Marne el Mariscal Joffre había dicho al ejército francés en su orden del día: "Nadie deberá retroceder ni un solo paso." Cerca de Soisson, entre las ruinas de una aldea devastada por la guerra, una compañía de infantería, fiel a la orden impartida y a la consigna de sus jefes, obedeciendo ciega y sin reflexión al Capitán que la mandaba, permaneció impasible en su sitio, a pesar de la irresistible avalancha de los alemanes, que atacaban impetuosamente en todo el frente, y no obstante advertir que la línea francesa cedía terreno al enemigo.

El suelo se hallaba minado, en una larga extensión, con fuertes cargas explosivas eléctricas.

De improviso, cuando la compañía en orden cerrado efectuaba uniformes y disciplinadas descargas, como si se hallara en un polígono, bajo el imperio de la voz de mando del oficial, abrióse en una horrenda explosión el suelo en que hallaban aquellos soldados dignos de Esparta, y los miserables restos de murallas se confabularon también para sepultarlos, cayendo pesadamente sobre ellos.

El señor don Augusto Orrego Luco, que relata esta anécdota que es historia viva, en su hermoso libro Por los campos de Batalla, dice que, sobre las bayonetas, que quedaron refulgiendo al sol, los americanos residentes en Francia construyeron un majestuoso monumento de mármol blanco, con esta sencilla y decidora inscripción:

\section{A la memoria del soldado francés que duerme debajo, en pie, con el fusil en la mano.}

Sus hermanos de la América.

Pero para llegar a este heroísmo había sido necesario que 
transcurrieran varios siglos de educación militar en que se ejercitaba una bien entendida disciplina, que hacía de cada soldado, no una máquina ni un ente, sino un hombre capaz de pensar y más dócil a la palabra amable que al insulto o al látigo.

\section{VI.-QUÉ ES UNA RETIRADA EN LA REALIDAD}

Franz Schawecher dice un su libro En la boca de la muerte ya citado:

No hay nada que destroce más la moral de una tropa que una retirada. ¿Retirada? Es un martillazo. No es retroceder voluntariamente; es huir. Es sentirse derrotado; jes el caos! Todo el ejército se conmueve hasta su base; todo peligra en disolverse, itodo! Es la fuga; es el derrumbe.

Me tocó tomar parte durante la guerra en dos retiradas, una vez en la retirada de dos divisiones durante la batalla de Praszuys, en el frente ruso, y en la gran retirada del ejército en Francia, en el verano y otoño de 1918.

En el primer caso, en Marzo de 1915, se trataba de una retirada estratégica, por orden superior. Estábamos en terreno desfavorable ante un enemigo 14 veces superior. Algunas tropas debían cubrir la retirada; entre éstas se hallaba mi regimiento. El enemigo nos seguía de cerca. Muy luego se notó la desorganización.

Las tropas, en vista de que veían retirarse a los demás, se desmoralizaban. Hubo pronto una gran confusión; nadie obedecía la voz de los oficiales. Los soldados parecían atontados o enloquecidos, mientras las bajas aumentaban y aumentaban considerablemente.

La gran retirada en Francia, en 1918, se empezó oponiendo tenaz resistencia, lo que se conoce militarmente hoy como defensa dilatoria. Luego después se desalojaban materialmente las posiciones, aterrorizadas las tropas. Empezaron las deserciones. Algunos se negaban a combatir, otros se entregaban prisioneros voluntariamente. Fué la época cruel en que la revolución en la patria había carcomido en su base al ejército invencible, quitándole el suelo bajo sus pies.

Después de leer esto, todo soldado profesional podría convertirse en un escéptico si no estuviera acorazado de entusias mo guerrero (de espíritu militar) y si no hubiera visto en los nuevos reglamentos tácticos exaltar hasta el delirio el bello principio de la ofensiva: jatacar, siempre atacar! El que ataca, impone su ley al adversario.

\section{VII.-ENSEÑANZAS MILITARES DE LA GUERRA}

Es muy sabido ya el hecho de que la guerra europea constituyó una fuente inagotable de experiencia militar, durante los cuatro años de su duración y aun después, cuando esas 
experiencias recogidas pudieron ordenarse y estudiarse, a conciencia, con serenidad y buen juicio. Hoy en día el factor moral-las fuerzas psicológicas de las naciones beligerantestiene una importancia decisiva en el desarrollo de una campaña. Y más tarde, sirven de enseñanza y guían el estudio científico de las operaciones llevadas a cabo.

Gustavo Le Bon dice en su obra Enseñanzas psicológicas de la guerra europea:

Desde el punto de vista de la bravura la guerra nos ha permitido distinguir toda una extensa gama de cualidades hasta ahora clasificadas en nuestro entendimiento en un conjunto algo confuso. La más bella cualidad de de la bravura es aquella que permite a un hombre, partiendo de la seguridad y sin excitación para la lucha, lanzarse con una voluntad fríamente calculada a un peligro conocido y medido. El verdadero valor es prudente y no se ejerce sino en el límite de la necesidad, sin fanfarronería inútil.

\section{Y en otra parte agrega:}

La guerra actual es una lucha de antagonismos psicológicos. Ideales inconfundibles son los que luchan: la libertad individual se yergue contra la tiranía estatista, los antiguos usos de lealtad interracional y respeto de los tratados, contra la supremacía de los cañones.

En el análisis de esta fuerzas psicológicas actuando en medio de las batallas, las novelas de la guerra, es decir, las ideas de los escritores, restándoles sólo la fantasía, han construído un auxiliar poderoso en los gabinetes militares de la post-guerra.

\section{VIII.-ENSEÑANZAS LITERARIAS DEL TEMA DE LA GUERRA}

Cuando el tema de la guerra se ha puesto de moda es porque los escritores han visto en él vasto campo de acción y porque los lectores de todas las razas han creído reconocer algo propio o por lo menos algo capaz de hacerles vibrar.

La guerra ha proporcionado los más variados y hasta encontrados tópicos interesantes para los novelistas, y es preciso reconocer que, efectivamente, el tema es en sí inagotable. Desde el cuadro crudo, cruel, impreso en las retinas de Barbusse o de Remarque, hasta la vida de las Etapas, en la obra de Glaeser, ha dado la guerra la nota triste o lúgubre, o monótona y desesperante - ique mucho de la guerra es espera e incertidumbre! - $u$ horrenda $y$ desconcertante en las páginas de Los que teníamos doce años.

Por una u otra causa el tema de la guerra interesa a todos los 
lectores de todos los países: de ahí el éxito-que no debiera asombrarnos-de las novelas de la guerra; especialmente de aquellas que-como Sin novedad en el frente-han mirado el tema desde el punto de vista más hondamente humano y más universal.- J. M. VARAS C A L O.

\section{RECUERDOS DE LEONIDAS ANDREIEF}

通N la primavera del año 1898 leí en un diario de Moscú, El Correo, el cuento Bergamot y Garaska, un cuento pascual, de un tipo bastante corriente; dirigido al corazón de un lector empascuado, recordaba una vez más que el hombre tiene a su alcance-a veces en casos especiales-el sentimiento noble que lo convierte en amigo de sus enemigos, aunque no sea por mucho tiempo, digamos no más que por un día.

Desde los tiempos del cuento El Capote de Gogol, los escritores rusos habrán seguramente escrito varios cientos, sino miles de estos cuentos enternecedores. Alrededor de las flores maravillosas de la verdadera literatura rusa, ellos son como los "dientes de león», los cuales, según parece, deben decorar la mísera vida del alma rusa, enferma y dura (1).

Pero en este cuento noté un fuerte aire de talento, el cual me recordó en algo a Pamialovsky, y además de esto, se notaba una sonrisita, apenas perceptible, de incredulidad hacia el hecho, y esta sonrisita lo conformaba a uno con el,sentimentalismo inevitable de la literatura "pascual» y de Navidad.

Yo le escribí al autor unas palabras acerca del cuento, y recibí una contestación divertida de Andreief; me escribía, con una escritura original, medio imprimiendo las letras, palabras alegres y graciosas, entre las cuales se destacaba un aforismo, sencillo, pero escéptico:

Para un hombre satisfecho es tan agradable demostrar grandeza de alma, como lo es tomar café después de comida.

De aquí empieza mi amistad con Leonidas Nicolaevich Andreief. Durante el verano leí varios otros cuentos suyos y los folletos de Jaime Lynch, observando lo ligero que se desarrollaba el talento original del nuevo escritor.

(1) Seguramente que en aquel tiempo no pensaba como estoy escribiendo ahora, pero no es interesa nte recordar mis ideas antiguas. 